\title{
ANALGESIC AND ANTI-INFLAMMATORY ACTIVITY OF NEW ANALOGS OF HC-030031: A TRPA1 CHANNEL ANTAGONIST
}

\author{
ADRIAN BRYŁA ${ }^{\prime *}$, MARIETTA ŚLUSARCZYK ${ }^{2}$, MAŁGORZATA ZYGMUNT', \\ GRAŻYNA CHŁOŃ-RZEPA² ${ }^{2}$ and GRZEGORZ KAZEK ${ }^{1}$
}

\author{
${ }^{1}$ Department of Pharmacological Screening, \\ ${ }^{2}$ Department of Medicinal Chemistry, \\ Jagiellonian University, Medical College, Cracow, Poland
}

\begin{abstract}
One of our study direction is research in the group of compounds affecting the TRPA1 ion channel (Transient receptor potential cation channel, subfamily A, member 1) which can perform an important function in pain (including neuropathic pain) and inflammation for example in asthma and other chronic respiratory diseases. The aim of this study was to evaluate the analgesic and anti-inflammatory activity of two analogs of HC030031 analogs belonging to nitrogen derivatives of the heterocyclic system: xanthine (compound 1) and benzimidazole (compound 2) with hydrazide and amide moieties respectively. In this paper, for two derivatives (compound $\mathbf{1}$ and compound $\mathbf{2}$ ) potential analgesic and anti-inflammatory/anti-edematous activities were evaluated in animal models of pain in mice (writhing response test, formalin test) and inflammation in rats (carrageenan-induced paw edema test). Both the tested compounds $\mathbf{1}$ and $\mathbf{2}$ showed significant analgesic and antiinflammatory activities.
\end{abstract}

Keywords: TRPA1 channels, HC-030031 analogs, inflammation, pain

Analgesics are substances that reduce the feeling of pain which can arise due to the action of a mechanical, thermal, chemical or electrical stimulus that exceeds the pain threshold. Pain may be the result of irritation of pain receptors (nociceptors), reduction of their excidility threshold (receptor pain), damage of the structures of the nervous system (neuropathic non-receptor pain) or pain felt despite the lack of tissue damage (psychogenic nonreceptor pain) (1).

Inflammatory pain appears as a result of the inflammatory process or tissue damage. It occurs in the form of resting pain, allodynia and hyperalgesia. The inflammatory process arises in response to harmful factors: physical, chemical or as a result of infection with parasites or microbes. Infected and damaged tissue reacts with inflammation. It is a series of cellular and vascular reactions and defense reactions that can be specific and non-antigen-specific. The inflammatory reaction is characterized by five basic symptoms: redness, edema, local increase in body temperature, pain, decline of function (2). Despite many drugs used in the pharmacotherapy of pain, their clinical effectiveness is not sufficient for some pain conditions. The rapid acquisition of analgesic tolerance, addiction to opioid analgesics and numerous side effects are the reason of searching for new effective analgesics with greater safety.

One of such study direction is research in the group of compounds affecting the TRPA1 ion channel which can perform an important function in pain (including neuropathic pain) and inflammation for example in asthma and other chronic respiratory diseases. TRPA1 channels are activated not only by several exogenous activators, such as allyl isothiocyanate (AITC), allicin, or cinnamaldehyde but also by a variety of endogenous agonists produced during tissue injury and inflammation, for example, formalin, formaldehyde, nitro-oleic acid, and arachidonic acid nonmedolizable analog. Prostaglandins, bradykinin, and reactive oxygen species have all been shown to act as TRPA1 agonists, which suggest their role in integrating inflammatory pain.

Transient receptor potential ankyrin 1 is one of the 28 members of the transient receptor potential (TRP) channel family and the sole member of the

\footnotetext{
* Corresponding author: e-mail:adrian.bryla@interia.pl
} 


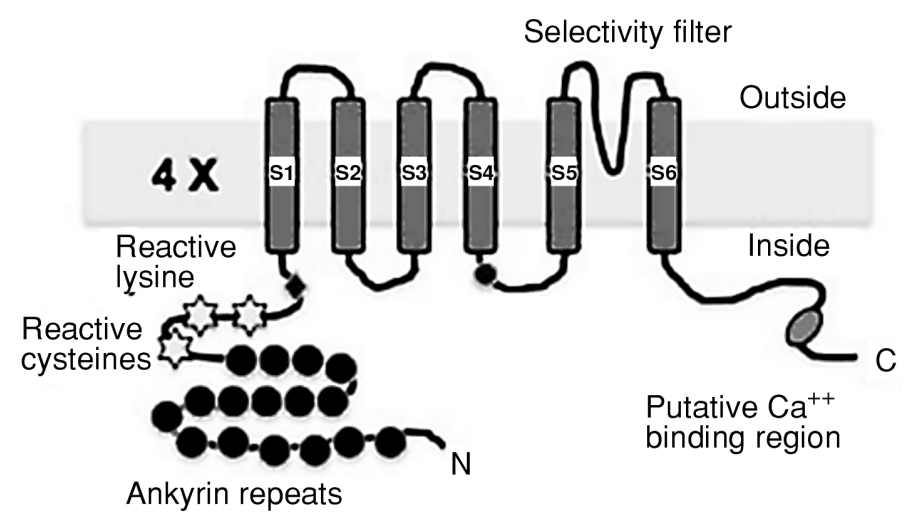

Figure 1. Structure of the TRPA1 channel (5).<smiles>CC(C)c1ccc(NC(=O)Cn2cnc3c2c(=O)n(C)c(=O)n3C)cc1</smiles>

Figure 2. Structure of TRPA1 antagonist HC-030031.

TRPA subfamily in mammals. Like all TRP channels, TRPA1 possesses a tetrameric structure with a single pore present at the central axis. Each subunit contains six transmembrane alpha-helices (labeled S1-S6) and intracellular $\mathrm{N}$-terminal and $\mathrm{C}$-terminal domains. The pore-forming selectivity filter is positioned between the S5 and S6 transmembrane helices. TRPA1 is unusual among mammalian TRP channels in having a very long ankyrin repeat within the $\mathrm{N}$-terminal domain (14-18 ankyrin repeats depending on species). TRPV and TRPC channels also have N-terminal ankyrin repeats, although they are much shorter (three to six repeats). TRPA1 is permeable to both monovalent and divalent cations, and therefore, TRPA1 is capable of depolarizing the membrane and initiating $\mathrm{Ca}^{2+}$ signaling in the cells it is expressed $(3,4)$.

\section{The aim of study}

Among the significant number of compounds that have been identified as TRPA1 antagonists, only some, for example, xanthine based acetamides (e.g. HC-030031) (Fig. 2) have shown efficacy in animal models of acute, inflammatory and neuropathic pain.
The aim of this study was to evaluate the analgesic and anti-inflammatory activity of two analogs of HC-030031 belonging to nitrogen derivatives of the heterocyclic system: xanthine (compound 1) and benzimidazole (compound 2) with hydrazide and amide moieties respectively.

\section{Animals}

The in vivo experiments were carried out on male CD-1 mice weighing 18-26 g and male rats Wistar weighing 150-180 g. The animals were housed in constant temperature facilities exposed to 12: 12 light-dark cycle and maintained on a standard pellet diet and tap water given ad libitum. Control and experimental groups consisted of 6-8 animals each. The investigated compounds were administered intraperitoneally (i.p.) in the form of a suspension in $0.5 \%$ methylcellulose (MC)

\section{Chemistry}

Structures of the compounds $\mathbf{1}$ and $\mathbf{2}$ and methods for their preparation are presented in Schemes 1 and 2. The novel 2-(1,3-dimethyl-2,6-dioxo-1,2,3,6tetrahydro-7H-purin-7-yl)-N'-(4-isopropylbenzylidene)acetohydrazide (compound 1) was synthesized in a multistep procedure according to Scheme 1.

In the first step, commercially available 1,3dimethyl-2,3,6,7-tetrahydro-1H-purine-2,6-dione (theophylline) was treated with ethyl chloroacetate, in the presence of potassium carbonate $\left(\mathrm{K}_{2} \mathrm{CO}_{3}\right)$ and catalytic amount of benzyltriethylammonium chloride (TEBA) in refluxing acetone to yield ester $\mathbf{I}$. Then the resulting ester I was treated with hydrazine hydrate in anhydrous ethanol to obtain hydrazide II. In the final step, the condensation reaction between hydrazide II and 4-isopropylbenzaldehyde in anhydrous ethanol and catalytic amount of $\mathrm{HCl}$ took place to yield the designed compound $\mathbf{1}$. 
The previously reported (6) 2-(1H-benzimidazol-1-yl)-N-(4-(tert-butyl)phenyl)acetamide (compound 2; Scheme 2) was obtained according to described method $(7,8)$. In the first step, $1 \mathrm{H}$-benzimidazole was alkylated in the 1-position with ethyl chloroacetate, yielded ester III. In the next step, this ester was hydrolyzed using $\mathrm{KOH}$ and then acidified with concentrated $\mathrm{HCl}$ to obtain the acid IV. In the final step, the obtained acid was treated with 4-(tertbutyl)aniline in the presence of $\operatorname{di}(1 \mathrm{H}$-imidazol-1yl)methanone (CDI), yielded the compound 2.

\section{EXPERIMENTAL}

\section{Chemistry}

All the reagents and solvents were purchased from Sigma-Aldrich, TCI Europe or Fluorochem. Thin-layer chromatography was performed on Merck silica gel $60 \mathrm{~F}_{254}$ aluminum sheets (Merck, Darmstadt, Germany) with the following solvent A: dichloromethane/methanol $(9.5: 0.5)$. Spots were detected by their absorption under UV light (ë = $254 \mathrm{~nm}) .{ }^{1} \mathrm{H}$ NMR spectra were recorded on JEOL FT-NMR $500 \mathrm{MHz}$ apparatus at $500 \mathrm{MHz}$, using TMS $(0.00 \mathrm{ppm})$ as an internal standard and DMSO- $d_{6}(2.25 \mathrm{ppm})$ as a solvent. Chemical shifts were expressed in $\delta$ (ppm) and the coupling constants $J$ in Hertz $(\mathrm{Hz})$. Splitting patterns are designated as follows: s (singlet), $\mathrm{d}$ (doublet). LC/MS analyses were performed on Waters Acquity TQD apparatus with eë DAD detector. For mass spectrometry, ESI+ (electrospray positive) ionization mode was used. UV spectra were taken in the range of 200$700 \mathrm{~nm}$. The UPLC, as well as MS purity of all the investigated compounds, was determined to be over 98\%. Melting points (mp) were determined using a Büchi apparatus and are uncorrected.

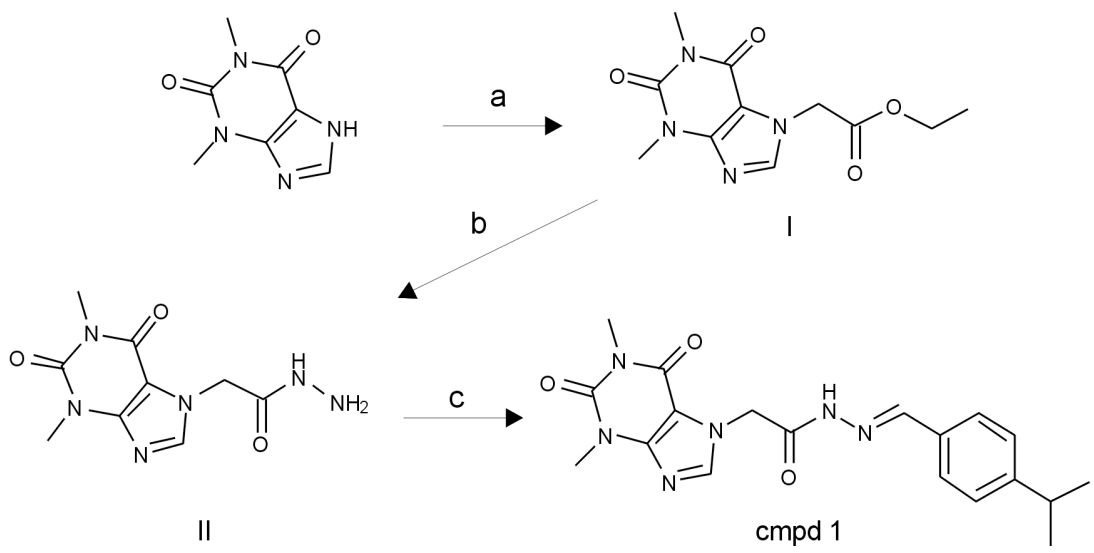

Scheme 1. The synthesis of compound 1. Reagents and conditions: (a) ethyl chloroacetate, $\mathrm{K}_{2} \mathrm{CO}_{3}$, TEBA, acetone, reflux, $15 \mathrm{~h}$; (b) hydrazine hydrate, anhydrous ethanol, reflux, $20 \mathrm{~h}$; (c) 4-isopropylbenzaldehyde, ethanol, $\mathrm{HCl}$, rt., $72 \mathrm{~h}$.<smiles>c1ccc2[nH]cnc2c1</smiles>

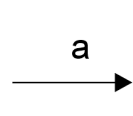<smiles>CCOC(=O)Cn1cnc2ccccc21</smiles>

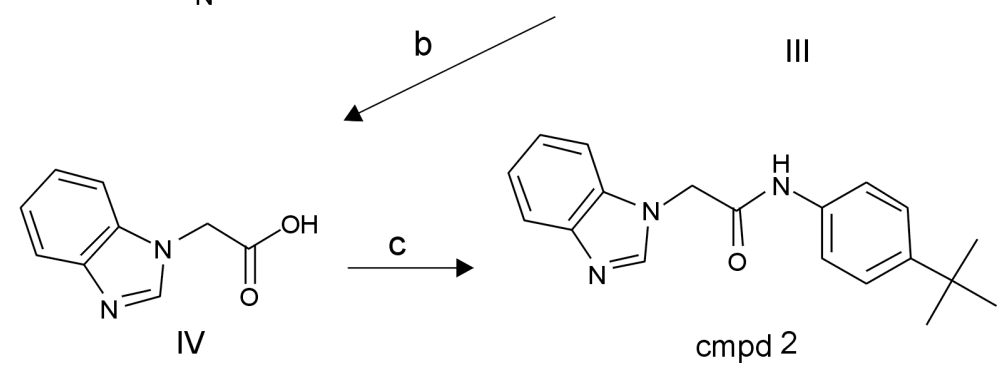

Scheme 2. The synthesis of compound 2 . Reagents and conditions: (a) ethyl chloroacetate, $\mathrm{K}_{2} \mathrm{CO}_{3}$, TEBA, acetone, reflux; (b) $\mathrm{KOH}$, acetone/ $\mathrm{H}_{2} \mathrm{O}$, conc. $\mathrm{HCl}$, reflux; (c) 4-(tert-butyl)aniline, DMF, CDI, rt., $72 \mathrm{~h}$. 


\section{Synthesis of intermediates I and II}

The ethyl 2-(1,3-dimethyl-2,6-dioxo-1,2,3,6tetrahydro-7H-purin-7-yl)acetate (I) (9) and 2-(1,3dimethyl-2,6-dioxo-1,2,3,6-tetrahydro-7H-purin-7yl) acetohydrazide (II) (9) were prepared by following the procedure shown in Scheme 1 according to the previously reported methods $(10,11)$. The intermediates I and II were structurally characterized and matching with the reported results (9).

Synthesis of 2-(1,3-dimethyl-2,6-dioxo-1,2,3,6tetrahydro-7H-purin-7-yl)-N'-(4 isopropylbenzylidene)acetohydrazide (compound 1)

A mixture of hydrazide II (1 mmol), 4-isopropylbenzaldehyde $(1 \mathrm{mmol})$ and 2 drops of con. $\mathrm{HCl}$ was stirred in ethanol $(10 \mathrm{~mL})$ at room temperature for three days. Next, water was added $(40 \mathrm{~mL})$ and the resulting precipitate was filtered off and purified by crystallization from water.

White solid; yield $94 \%$; mp $238-239^{\circ} \mathrm{C} ; R_{f}=$ 0.59 (A); ${ }^{1} \mathrm{H}$ NMR (500 MHz, DMSO- $\left.d_{6}\right) \delta \mathrm{ppm}$ 1.17 (d, $\left.J=6.90 \mathrm{~Hz}, 6 \mathrm{H}, \mathrm{CH}\left(\mathrm{CH}_{3}\right)_{2}\right), 3.16$ (s, 3H, $\left.\mathrm{N}^{1} \mathrm{CH}_{3}\right), 3.41\left(\mathrm{~s}, 3 \mathrm{H}, \mathrm{N}_{3} \mathrm{CH}_{3}\right), 5.08(\mathrm{~s}, 1 \mathrm{H}$, $\left.\mathrm{CH}\left(\mathrm{CH}_{3}\right)_{2}\right), 5.49$ (s, 2H, $\left.\mathrm{N}_{7} \mathrm{CH}_{2}\right), 7.29$ (d, $J=8.16$ $\mathrm{Hz}, 2 \mathrm{H}, 3,5-\mathrm{Ph}), 7.61$ (d, $J=8.23 \mathrm{~Hz}, 2 \mathrm{H}, 2,6-\mathrm{Ph})$, 7.98 (s, 1H, NHNCH), 8.03 (s, 1H, $\left.\mathrm{C}_{6} \mathrm{H}\right), 11.69$ (s, $1 \mathrm{H}, \mathrm{NHNCH})$; LC/MS: $\mathrm{m} / \mathrm{z}$ calc. 383.18 , found 383.20. Formula: $\mathrm{C}_{19} \mathrm{H}_{22} \mathrm{~N}_{6} \mathrm{O}_{3}$ (382.41).

\section{Synthesis of intermediates III and IV}

The ethyl 2-(1H-benzimidazol-1-yl)acetate (III) (12) and 2-(1H-benzimidazol-1-yl)acetic acid (IV) (13) were prepared by following the procedure shown in Scheme 2 according to the previously reported methods $(7,8)$.

The intermediates III and IV were structurally characterized and matching with the reported results.

Synthesis of 2-(1H-benzimidazol-1-yl)-N-(4-(tertbutyl)phenyl)acetamide (compound 2)

A mixture of acid IV (2 mmol) and CDI (3 $\mathrm{mmol})$ in DMF (5 mL) was stirred at room temperature for $30 \mathrm{~min}$. Afterward, 4-(tert-butyl)aniline (2 mmol) was added and then stirred at room temperature for 3 days. After completion 2-3 drops of water were added and the solvent was evaporated under reduced pressure. The crude product was purified by column chromatography using the solvent A.

\section{Pharmacology \\ The formalin test}

The mice were pretreated with the tested compound or the vehicle (1\% Tween 80$)$ and were allowed to acclimate in Plexiglas observation chambers $(20 \times 30 \times 15 \mathrm{~cm})$ for $60 \mathrm{~min}$ before the test. The investigated compounds were administered at a dose of 20,10, $5 \mathrm{mg} / \mathrm{kg}$ b.w. i.p. (as a suspension in methylcellulose). Then, $20 \mu \mathrm{L}$ of a $5 \%$ formalin solution was injected intraplantarly into the right hind paw using a 26-gauge needle. Immediately after formalin injection, the animals were placed individually into glass beakers and were observed during the next $30 \mathrm{~min}$. Time (in seconds) spent on licking or biting of the injected paw in selected intervals, 0-5, 15-20, 20-25, and 25-30 min, was measured in each experimental group and was an indicator of nociceptive behavior (14). The $\mathrm{ED}_{50}$ values and their confidence limits were estimated by the method of Litchfield and Wilcoxon (15). As a reference compound acetylsalicylic acid was used in this experiment.

\section{Writhing response test}

The investigated compounds were administered at a dose of 20,10,5 and 2.5 (one compound) $\mathrm{mg} / \mathrm{kg}$ b.w. i.p. (as a suspension in methylcellulose) $1 \mathrm{~h}$ before administration of phenylbenzoquinone. Phenylbenzoquinone (PBQ) or vehicle (1\% Tween 80) was injected into the peritoneal cavities of mice. Each mouse was placed in a large glass cylinder and the intensity of nociceptive behavior was quantified by counting the total number of writhes (contraction of the abdominal muscle together with stretching of hind limbs or rotation of the trunk) occurring between 0 and $20 \mathrm{~min}$ after stimulus injection. The intensity of the writhing response was expressed as the cumulative number of writhings at 2 min interval over $20 \mathrm{~min}$ or the total writhing over $20 \mathrm{~min}$ (16). As a reference compound acetylsalicylic acid was used in this experiment.

\section{Carrageenan-induced edema model}

Rats were divided into four groups, one of them being the control. In order to produce inflammation, $0.1 \mathrm{~mL}$ of $1 \%$ carrageenan solution in water was injected ( $1 \mathrm{~h}$ after administration of tested compound). The investigated compounds were administered at a dose of $20 \mathrm{mg} / \mathrm{kg}$ b.w. i.p. (as a suspension in methylcellulose) into the hind paw subplantar tissue of rats, according to the modified method of C. A. Winter and P. Lence $(17,18)$. The development of paw edema was measured with a plethysmometr (Plethysmometr 7140, Ugo Basile). Prior to the administration of test substances, paw diameters were measured by dividers and recorded. The investigated compounds were administered at a dose of $20 \mathrm{mg} / \mathrm{kg}$, i.p. (as a suspension in methylcellulose), 
prior to carrageenan injection. Methylcellulose was administered by the same route, to the control group (methylcellulose had no effect on edema, data not shown). After these administrations, paw diameters were measured at 1,2 , and $3 \mathrm{~h}$. The edema $\%$ and edema inhibition \% were calculated according to the formulas given below:

Edema $\%=\left(\mathrm{N}^{\prime} \times 100\right) / \mathrm{N}$

Edema inhibition $\%=\left(\mathrm{N}-\mathrm{N}^{\prime} \times 100\right) / \mathrm{N}$

$\mathrm{N}$ : paw diameters measured 1, 2 and $3 \mathrm{~h}$ after injection of carrageenan to the control group - paw diameters at the beginning.

$\mathrm{N}$ ': paw diameters measured 1,2 , and $3 \mathrm{~h}$ after injection of carrageenan to the test groups - paw diameters at the beginning. As a reference compound, ketoprofen was used in this experiment.

\section{RESULTS}

\section{Antinociceptive activity in the formalin test}

In the formalin test which is a model of chronic pain induced by the administration of 5\% formalin solution, the evaluated compounds showed antinociceptive activity (Table 1).

The injection of formalin into the dorsal surface of the hind paw of a mouse produces a biphasic nocifensive behavioral response, i.e. licking, biting, flinching, or lifting the injected paw. The acute (neurogenic) nociceptive phase lasts for the first 5 min and is followed by a period of little activity during the next $10 \mathrm{~min}$. The first phase of the test is directly associated with the stimulation of nociceptors and the development of neurogenic inflammation. The second (late) phase occurs between 15 and $30 \mathrm{~min}$ after formalin injection. The second phase is dependent on peripheral inflammation and central sensitization of pain. Since this phase reflects the activation of inflammatory processes, the compounds active in this phase of the experiment have also anti-inflammatory effect.

Compounds 1 and $\mathbf{2}$ showed antinociceptive effect only seen in the second phase of the test. In the first phase, compounds $\mathbf{1}$ and $\mathbf{2}$ were active only at a dose of $20 \mathrm{mg} / \mathrm{kg}$. All tested compounds showed stronger effect antinociceptive and anti-inflammatory than ASA which $\mathrm{ED}_{50}=126.3 \mathrm{mg} / \mathrm{kg}$.

\section{Peripheral analgesic activity in the ,writhing syn-} drome" test induced by phenylbenzoquinone

Writhing test is a chemical method used to induce pain of peripheral origin by injection of irritant principles like phenylbenzoquinone.

The evaluated compounds showed analgesic activity (Table 2). The present study demonstrated that all tested compounds decreased statistically significant number of writhings of mice in response to phenylbenzoquinone. Compounds $\mathbf{1}$ and $\mathbf{2}$ were active at dose of $20 \mathrm{mg} / \mathrm{kg}, 10 \mathrm{mg} / \mathrm{kg}$ and $5 \mathrm{mg} / \mathrm{kg}$. More effective is compound 2 which value of $\mathrm{ED}_{50}$ is 4.2 $\mathrm{mg} / \mathrm{kg} / \mathrm{b}$.w. As a reference compound was used acetylsalicylic acid (ASA).

Table 1. The influence of the investigated compounds on the duration of pain reaction in the formalin test in mice.

\begin{tabular}{|c|c|c|c|c|c|c|c|}
\hline \multirow[t]{2}{*}{ Compound } & \multirow{2}{*}{$\begin{array}{c}\text { Dose } \\
{[\mathrm{mg} / \mathrm{kg}]}\end{array}$} & \multicolumn{2}{|c|}{$\begin{array}{l}\text { Time }[\mathrm{sec}] \text { spent on licking or } \\
\text { biting the injected paw } \pm \text { SEM }\end{array}$} & \multicolumn{2}{|c|}{ Inhibition [\%] } & \multicolumn{2}{|c|}{$\begin{array}{c}\mathrm{ED}_{50} \\
{[\mathrm{mg} / \mathrm{kg} \text { b.w.] }}\end{array}$} \\
\hline & & Phase I & Phase II & Phase I & Phase II & Phase I & Phase II \\
\hline Control & - & $41.0 \pm 3.0$ & $133.9 \pm 8.7$ & - & - & - & - \\
\hline \multirow{3}{*}{ Compound 1} & 20 & $13.6 \pm 0.7^{\mathrm{c}}$ & $53.3 \pm 3.5^{\mathrm{c}}$ & 66.8 & 60.2 & \multirow{3}{*}{ - } & \multirow{3}{*}{14.0} \\
\hline & 10 & $32.8 \pm 3.1$ & $61.8 \pm 9.2^{c}$ & 20.0 & 46.2 & & \\
\hline & 5 & $42.3 \pm 1.4$ & $121.3 \pm 11.3^{b}$ & 0.0 & 9.4 & & \\
\hline \multirow{3}{*}{ Compound 2} & 20 & $15.5 \pm 1.6^{\mathrm{c}}$ & $3.3 \pm 2.2^{\mathrm{c}}$ & 62.2 & 97.5 & \multirow{3}{*}{ - } & \multirow{3}{*}{5.3} \\
\hline & 10 & $47.8 \pm 2.6$ & $8.3 \pm 2.6^{c}$ & 0.0 & 93.8 & & \\
\hline & 5 & $50.3 \pm 3.4$ & $84.6 \pm 13.5$ & 0.0 & 36.8 & & \\
\hline Control & - & $63.8 \pm 2.0$ & $120.8 \pm 3.4$ & - & - & - & - \\
\hline \multirow{3}{*}{ Acetylsalicylic acid } & 200 & $62.0 \pm 8.6$ & $40.6 \pm 14.0^{\mathrm{b}}$ & 2.8 & 66.4 & \multirow{3}{*}{ - } & \multirow{3}{*}{126.3} \\
\hline & 100 & $58.5 \pm 4.5$ & $60.3 \pm 9.5^{\mathrm{b}}$ & 8.3 & 50.1 & & \\
\hline & 50 & $59.8 \pm 6.3$ & $108.7 \pm 13.8$ & 6.3 & 10.0 & & \\
\hline
\end{tabular}

Data are presented as the means \pm SEM of 6-8 mice per group. Statistical analysis: one-way analysis of variance (ANOVA), followed by Dunnett's post hoc comparison. Significance: ${ }^{\mathrm{a}} \mathrm{p}<0.05,{ }^{\mathrm{b}} \mathrm{p}<0.01,{ }^{\mathrm{c}} \mathrm{p}<0.001 \mathrm{vs}$. control. 
Anti-inflammatory (antiedematous) effect in the carrageenan-induced edema model

Two compounds were evaluated in the carrageenan-induced edema test. Compounds were administered at a dose of $20 \mathrm{mg} / \mathrm{kg}$ body weight. Ketoprofen (administered i.p. at a dose of 20 $\mathrm{mg} / \mathrm{kg} / \mathrm{b}$.w.) was used as a reference compound. All tested compounds decreased the volume of edema induced by s.c.carrageenan injection into the hind paw of rats (Table 3 ).

The carrageenan test is used to evaluate the anti-inflammatory effect. Injection of the compound into the hind paw of an animal induces long-lasting edema.

The present study on the carrageenan-induced paw edema model demonstrated that two tested compounds decreased the volume of edema induced by carrageenan injection into the hind paw of rats.
Stronger anti-inflammatory effect in this assay was produced by compound $\mathbf{1}$. A statistically significant effect was observed in the $2^{\text {nd }}$ and $3^{\text {rd }} \mathrm{h}$ of the experiment, inhibiting edema development by $54.0 \%$ and $64.0 \%$. Compound 2 a statistically significant to reduced the paw edema in the $3^{\text {rd }} \mathrm{h}$ of the experiment, inhibiting edema development by $44.8 \%$, respectively.

\section{DISCUSSION AND CONCLUSION}

The aim of this study was to evaluate the analgesic and anti-inflammatory activity of two analogs of HC-030031 belonging to nitrogen derivatives of the heterocyclic system: xanthine (compound 1) and benzimidazole (compound 2) with hydrazide and amide moieties respectively.

The analgesic activity of the compounds $\mathbf{1}$ and 2 was measured using the formalin test. The first

Table 2. The influence of the investigated compounds on the pain reaction in the "writhing syndrome" test in mice.

\begin{tabular}{|c|c|c|c|c|}
\hline Compound & $\begin{array}{c}\text { Dose } \\
{[\mathrm{mg} / \mathrm{kg}]}\end{array}$ & $\begin{array}{l}\text { Number of writhings } \\
\text { Mean } \pm \text { SEM }\end{array}$ & $\begin{array}{c}\text { Inhibition } \\
{[\%]}\end{array}$ & $\begin{array}{c}\mathrm{ED}_{50} \\
\text { [mg/kg b.w.] }\end{array}$ \\
\hline Control & - & $28.0 \pm 0.3$ & - & - \\
\hline \multirow{3}{*}{ Compound 1} & 20 & $4.3 \pm 0.5 c$ & 84.6 & \multirow{3}{*}{6.1} \\
\hline & 10 & $12.5 \pm 0.8^{\mathrm{c}}$ & 55.4 & \\
\hline & 5 & $14.4 \pm 1.1^{\mathrm{c}}$ & 48.6 & \\
\hline \multirow{4}{*}{ Compound 2} & 20 & $2.6 \pm 0.3^{\mathrm{c}}$ & 90.7 & \multirow{4}{*}{4.2} \\
\hline & 10 & $7.8 \pm 1.3^{\mathrm{c}}$ & 72.1 & \\
\hline & 5 & $11.7 \pm 1.3^{c}$ & 58.2 & \\
\hline & 2.5 & $26.7 \pm 0.6$ & 4.6 & \\
\hline Control & - & $21.5 \pm 0.7$ & - & - \\
\hline \multirow{3}{*}{ Acetylsalicylic acid } & 100 & $3.21 .2^{\mathrm{c}}$ & 85.1 & \multirow{3}{*}{39.1} \\
\hline & 50 & $8.51 .3^{b}$ & 60.5 & \\
\hline & 30 & $11.2 \quad 2.1$ & 47.9 & \\
\hline
\end{tabular}

Data are presented as the means \pm SEM of six to eight animals per group, ${ }^{\mathrm{a}} \mathrm{p}<0.05,{ }^{\mathrm{b}} \mathrm{p}<0.01,{ }^{\mathrm{c}} \mathrm{p}<0.001$. The results were analyzed by ANOVA test. ${ }^{\mathrm{a}} \mathrm{p}<0.05,{ }^{\mathrm{b}} \mathrm{p}<0.01,{ }^{\mathrm{c}} \mathrm{p}<0.001$ vs. control.

Table 3. Anti-inflammatory (antiedematous) effect of the compounds in the carrageenan-induced paw edema test.

\begin{tabular}{|c|c|c|c|c|}
\hline \multirow{2}{*}{ Compound } & \multirow{2}{*}{$\begin{array}{c}\text { Dose } \\
{[\mathrm{mg} / \mathrm{kg}]}\end{array}$} & $1 \mathrm{~h}$ & $2 \mathrm{~h}$ & $3 \mathrm{~h}$ \\
\cline { 3 - 5 } & - & $0.42 \pm 0.08$ & $0.89 \pm 0.11$ & $1.25 \pm 0.06$ \\
\hline Control & 20 & $0.34 \pm 0.08$ & $0.41 \pm 0.09 \mathrm{c}$ & $0.45 \pm 0.06 \mathrm{c}$ \\
\hline Compound 1 & 20 & $0.25 \pm 0.02$ & $0.65 \pm 0.08$ & $0.69 \pm 0.07 \mathrm{c}$ \\
\hline Compound 2 & 20 & $0.32 \pm 0.03$ & $0.41 \pm 0.04 \mathrm{a}$ & $0.43 \pm 0.03 \mathrm{~b}$ \\
\hline Ketoprofen & &
\end{tabular}

Data are presented as the means \pm SEM of six to eight animals per group, ap $<0.05$, bp $<0.01, \mathrm{cp}<0.001$. The results were analyzed by ANOVA test. ap $<0.05, \mathrm{bp}<0.01, \mathrm{cp}<0.001$ vs. control. 
phase of the formalin test (neurogenic/acute) occurs immediately after formalin administration, lasts 5 min and is connected with a direct stimulation of nociceptors whereas the second chronic phase of the formalin test (late, inflammatory) is a result of the activation of peripheral inflammatory processes and the spinal process of central sensitization to pain stimuli (14). Compounds $\mathbf{1}$ and $\mathbf{2}$ showed antinociceptive effect only seen in the second phase of the test. These effects were more pronounced than those observed following administration of the reference compound.

Studies demonstrated that all tested compounds showed analgesic activity in the ,writhing syndrome" test induced by phenylbenzoquinone. Tested compounds decreased the number of writhings of mice in response to phenylbenzoquinone. More effective was compound $\mathbf{2}$ which value of $\mathrm{ED}_{50}$ is $4.2 \mathrm{mg} / \mathrm{kg} / \mathrm{b}$.w. (9 times more active than reference compound).

The present study demonstrated that both examined compounds showed anti-inflammatory activity in the carrageenan-induced paw edema model. Two examinated compounds decreased the volume of edema induced by carrageenan injection into the hind paw of rats. Stronger anti-inflammatory effect in this assay was produced by compound $\mathbf{1}$. A statistically significant effect was observed in the $2^{\text {nd }}$ and $3^{\text {rd }}$ hour of the experiment, inhibiting edema development by $54.0 \%$ and $64.0 \%$. Due to the results obtained, these compounds will be subjected to further tests, for example, evaluation of the influence on TRPA1 ion channel.

\section{Acknowledgments}

This work was supported by the National Science Centre, Poland, grant No 2018/29/B/NZ7/ 00285 and Statutory Project of the Jagiellonian University No N42/DBS/000065.

\section{REFERENCES}

1. Wordliczek J., Dobrogowski J.: Leczenie bólu, PZWL, Warszawa 2007 (in Polish).

2. Mutschler E., Geisslinger G., Kroemer H.K., Ruth P., Schäfer-Korting M.: Farmakologia i Toksykologia, MedPharm Polska, Warszawa 2010 (in Polish).

3. Paulsen C.E., Armache J.P., Gao Y., Cheng Y., Julius D.: Nature 520, 511 (2015).

4. Madej M.G., Ziegler C.M.: Pflugers Arch. 470, 213 (2018).

5. Liao M., Cao E., Julius D., Cheng Y.: Nature 504, 107 (2013).

6. Besidski Y. et al.: PCT Int. Appl. WO 2004/100865 A2 2004/1125 (2004).

7. Chłoń-Rzepa G., Ślusarczyk M., Jankowska A., Gawalska A., Bucki A., et al.: Eur. J. Med. Chem. 158, 517 (2018).

8. Zygmunt M., Chłoń-Rzepa G., Sapa J., Pawłowski M., et al.: Pharmacol. Rep. 67, 9 (2015).

9. Maślankiewicz A., Syrek B., Nocun M., Pluta K., et al.: Acta Pol. Pharm. 36, 539 (1979).

10. Chłoń-Rzepa G., Jankowska A., Ślusarczyk M., Świerczek A., Pociecha K., et al.: Eur. J. Med. Chem. 146, 381 (2018).

11. Chłoń-Rzepa G., Jankowska A.W., Zygmunt M., Pociecha K., Wyska E., et al.: Heterocycl. Commun. 21, 273 (2015).

12. Sharma S.K., Sharma P.S.: Heterocycl. Lett 4, 571 (2014).

13. Mehendale N.P., Gowda P.T.: Int. Res. J. Pharm. 3, 189 (2012).

14. Kolesnikov Y., Cristea M., Oksman G., Torosjan A., Wilson R.: Brain Res. 1029, 217 (2004).

15. Litchfield J.T., Wilcoxon F.A.: J. Pharmacol. Exp. Ther. 96, 99 (1984).

16. Emele J.F., Shanaman J.E.: Arch. Int. Pharmacodyn. Ther. 170, 99 (1967).

17. Winter T., Risley E., Nuss G.: Proc. Soc. Exp. Biol. Med. 111, 544 (1962).

18. Lence P.: Arch. Int. Pharmacodyn. Ther. 136, 237 (1962).

(c) 2020 by Polish Pharmaceutical Society. This is an open access article under the CC BY NC license (c) (i) (8) (http://creativecommons.org/licenses/BY/4.0/). 